\title{
Unmanipulated haploidentical stem cell transplantation in adults with acute lymphoblastic leukemia: a study on behalf of the Acute Leukemia Working Party of the EBMT
}

Nicole Santoro ${ }^{1,2^{*}}$ (D) Annalisa Ruggeri ${ }^{1}$, Myriam Labopin ${ }^{1,3}$, Andrea Bacigalupo ${ }^{4,5}$, Fabio Ciceri ${ }^{6}$, Zafer Gülbaş ${ }^{7}$, He Huang ${ }^{8}$, Boris Afanasyev ${ }^{9}$, William Arcese ${ }^{10}$, Depei Wu$^{11}$, Yener Koc ${ }^{12}$, Johanna Tischer $^{13}$, Stella Santarone ${ }^{14}$, Sebastian Giebel ${ }^{15}$, Mohamad Mohty ${ }^{1}$ and Arnon Nagler ${ }^{3,16}$

\begin{abstract}
Background: Allogenic hematopoietic stem cell transplantation (allo-SCT) is the most effective post-remission treatment for adults with high-risk acute lymphoblastic leukemia (ALL). The aim of the study was to analyze results of unmanipulated haploidentical allo-SCT (haplo-SCT) for adults with ALL and to identify prognostic factors.

Methods: We performed a retrospective analysis on 208 adults transplanted in EBMT centers from 2007 to 2014.

Results: Median age at haplo-SCT was 32 years and median follow-up, 31 months. Forty-four percent of the patients were in first complete remission (CR1). Stem cell source was the bone marrow (BM) for $43 \%$ and peripheral blood (PB) for $57 \%$ of patients. Myeloablative conditioning (MAC) was used for $66 \%$ and reduced intensity regimen (RIC) for $34 \%$ of patients. GVHD prophylaxis was based on post-transplant cyclophosphamide (PT-Cy) for 118 (57\%) or on antithymocyte-globulin (ATG) for 90 (43\%) plus standard prophylaxis. One hundred eighty-four (92\%) patients achieved engraftment. Cumulative incidence (CI) of grade II-IV acute-graft-versus-host-disease (GVHD) was 31\%, grade III-IV 11\%, and chronic GVHD 29\%. Non-relapse mortality (NRM) and relapse-incidence (RI) were 32 and 37\%, respectively. Overall survival (OS), leukemia-free survival (LFS), and GVHD-free, relapse-free-survival (GRFS) at 3 years were 33, 31, and 26\%. For patients in CR1, OS, LFS, and GRFS were 52, 47, and 40\%, respectively. Disease status was the main factor associated with transplant outcomes. Use of BM was independently associated with improvement in NRM, acute GVHD, GRFS, LFS, and OS.
\end{abstract}

Conclusions: Unmanipulated haplo-SCT may be considered a valid option for adult patients with high-risk ALL lacking HLA identical donor preferably in early disease status.

Keywords: Non-TCD haploidentical, Allogenic stem cell transplantation, Acute lymphoblastic leukemia, Adults

\footnotetext{
*Correspondence: nicole.santoro24@gmail.com

Abstract presented in part as oral presentation during the plenary session of EBMT 2016, Valencia, Spain.

'Department of Hematology and Cell Therapy, Hôpital Saint-Antoine, 184

Rue du Faubourg Saint Antoine, 75012 Paris, France

2Department of Medicine, Division of Hematology and Clinical Immunology,

University of Perugia, Perugia, Italy

Full list of author information is available at the end of the article
} 


\section{Background}

Acute lymphoblastic leukemia (ALL) has a high frequency in children and young adults [1-3] and is rare in adults. Childhood ALL is associated with cure rates higher than $80 \%$, while in adult patients' cure rates range between 20 and $40 \%$ with high incidence of relapse and dismal prognosis $[4,5]$. Some of the differences between childhood and adult ALL are related to the biology of the disease, treatment, and patient-related factors. Adverse genetic features in adults predispose to chemotherapy resistance and disease relapse after an initial achievement of complete remission (CR). Other factors are the high incidence of comorbidities and treatment-related side effects that may result in the administration of lower cumulative doses of chemotherapy [4].

Approximately $80 \%$ of the patients with adult ALL achieve first CR (CR1); however, the major barrier to longterm survival is the disease recurrence which is over $60 \%$ with a median overall survival (OS) of $<10$ months [6].

Besides some controversy on indication and timing, allogenic hematopoietic stem cell transplantation (alloSCT) is the standard of care for high-risk patients in CR1 and all patients who experience relapse [7-12].

The most suitable donor for transplantation is an HLAmatched sibling or fully matched (10/10 HLA matched) unrelated donor (MUD). However, for patients who lack HLA matched sibling or MUD, allo-SCT from un haploidentical or cord blood donor, is a possible option [13, 14].

Haploidentical hematopoietic stem cell transplantation (haplo-SCT) is increasingly used [15] since it allows almost all patients in need for an allo-SCT to undergo allo-SCT. Haploidentical donors (siblings, children, parents, and extended relatives) are virtually available for all patients, and the access to further stem cell donations or donor lymphocyte infusions (DLIs) or other types of adoptive cellular therapies is easily available.

In the last decade, unmanipulated grafts without $\mathrm{T}$ cell depletion (TCD) have been used more frequently in the haplo-setting with the use of anti-thymocyte globulins (ATG) or post-transplant cyclophosphamide (PT-Cy) as GVHD prophylaxis with encouraging results [16-21]. Furthermore, the optimization of conditioning regimens with the development of reduced intensity conditioning (RIC) including for haplo-SCT, have further extended the use of haplo-SCT to older patients and those with significant pre-transplant comorbidities [22].

Several single-center- and registry-based studies showed comparable outcomes between haplo-SCT and mismatched (9/10 HLA compatibility) unrelated donor or cord blood transplants in patients with acute leukemias [23-25]. However, few studies, so far, analyzed the results of haplo-SCT in adult ALL.

In a recent report by Srour et al. [26], outcomes of 109 adults with ALL receiving haplo-SCT with PT-Cy as
GVHD prophylaxis were reported with encouraging results. We conducted a registry-based study of adults with ALL transplanted in EBMT centers using unmanipulated haplo-SCT with PT-Cy or ATG as GVHD prophylaxis and MAC or RIC as conditioning regimens.

\section{Methods \\ Study design}

This is a retrospective registry-based analysis on behalf of the ALWP of EBMT on haplo-SCT, in adult patients with ALL, performed between January 2007 and December 2014.

The EBMT is a voluntary working group of more than 500 transplant centers that are required to report all consecutive stem cell transplantations and follow-ups once a year. Audits are routinely performed to determine the accuracy of the data.

Patients included into the study, fulfilled all of the following criteria: age $\geq 18$ years; de novo ALL; first alloSCT, host-donor number of HLA mismatches $\geq 2$; peripheral blood (PB) or bone marrow (BM) grafts and no ex vivo T cell depletion.

Minimal residual disease (MRD) was defined as any evidence of detectable disease by cytogenetics, flowcytometry, and/or polymerase chain reaction (PCR) for patients in morphologic remission at transplant.

MAC was defined as a regimen containing either total body irradiation (TBI) with a dose greater than $6 \mathrm{~Gy}$, a total dose of oral busulfan $(\mathrm{Bu})$ greater than $8 \mathrm{mg} / \mathrm{kg}$, or a total dose of intravenous Bu greater than $6.4 \mathrm{mg} / \mathrm{kg}$ or melphalan at doses $>140 \mathrm{mg} / \mathrm{m}^{2}$. In addition, regimens containing two alkylating agents were considered as MAC. All other regimens were defined as RIC [27].

\section{Statistical analysis}

The primary endpoint was leukemia-free survival (LFS). Secondary endpoints were overall survival (OS), refined graft-versus-host-free, relapse-free survival (GRFS), neutrophil engraftment, acute (a)GVHD and chronic (c)GVHD, relapse incidence (RI), and non-relapse mortality (NRM).

LFS was defined as the interval from haplo-SCT to either relapse or death in remission. OS was defined as the time to death from all causes. GRFS events have been defined as grade $3-4$ acute GVHD, severe chronic GVHD, disease relapse, or death from any cause after SCT [28]. Engraftment was defined as the first of three consecutive days with an absolute neutrophil count $>0.5 \times 10^{9} /$. aGVHD was graded according to the modified Glucksberg criteria [29] and cGVHD according to the revised Seattle criteria [30].

Cumulative incidence (CI) of relapse and NRM was calculated from the date of transplant to the date of relapse or death in remission, respectively, with the other 
event being the competing risk. For studying GVHD, both relapse and death were considered as competing events.

Univariate comparisons of time-dependent endpoints were done using the log-rank test for OS and LFS and GRFS and the Gray's test for cumulative incidence functions.

A multivariate analysis was performed using Cox proportional hazards model. Variables were included in the multivariate model if they were conceptually important or if they approached or attained statistical significance by univariate analysis. All tests are two-sided. The type I error rate was fixed at 0.05 for determination of factors associated with time to event.

In order to test for a center effect, we introduced a random effect or frailty for each center into the model [31, 32].

Statistical analyses were performed with the SPSS 22 (SPSS Inc./IBM, Armonk, NY, USA) and R 3.2.3 ( $\mathrm{R}$ Development Core Team, Vienna, Austria) software packages.

\section{Results}

\section{Patients, disease, and transplant characteristics}

A total of 208 patients transplanted in 69 EBMT centers were analyzed, and a median of eight haplo-SCT for each center was reported. No center effect was found using the frailty model $(p=0.30)$. Patient, disease, and transplant characteristics are listed in Table 1.

The median follow-up was 31 (range 2-79) months, and the median year of haplo-SCT was 2012 (range 2007-2014). Median age at haplo-SCT was 32 (range 18-76) years. The majority of patients (69\%) had a Karnofsky performance status (KPS) $\geq 90 \%$. Fourteen (7\%) patients received a previous autologous SCT.

For patients with available information $(n=151), 100$ (66\%) patients had B ALL, and 51 (34\%) T ALL.

Disease status at transplantation was CR1 in 91 (44\%) patients, second or more complete remission (CR2+) in $58(28 \%)$ and $59(28 \%)$ patients were in active disease.

Cytogenetic analysis was available for 142 patients: 46 (32\%) were Philadelphia positive and 96 (68\%) were Philadelphia negative. Among Philadelphia negative patients, complete karyotype was reported for 69 patients. Thirty seven (54\%) had a normal karyotype and 32 (46\%) abnormal one. The most common alterations found were $t(1 ; 19)(n=5), t(4 ; 11)(n=4)$, and $t(12 ; 21)(n=2)$.

For patients with $t(9 ; 22)$, the use of tyrosine kinase inhibitors (TKI) was reported in 32 patients before transplant and in 11 patients after transplant, respectively.

Status of MRD at transplant for patients in CR was available for 91 of 149 patients, and 45 (49\%) were MRD positive.
Conditioning regimen was MAC in 137 patients (66\%) and RIC in 71 patients (34\%), respectively. Among chemotherapy-based regimen TBF (thiotepa $10 \mathrm{mg} / \mathrm{kg}$, fludarabine $150 \mathrm{mg} / \mathrm{m}^{2}$, busulfan $9.6 \mathrm{mg} / \mathrm{kg}$ i.v. for MAC; Thiotepa $5 \mathrm{mg} / \mathrm{kg}$ and busulfan $6.4 \mathrm{mg} / \mathrm{kg}$ i.v. for RIC) were the most commonly used regimens (Table 1 ).

GVHD prophylaxis was based on either PT-Cy in 118 $(57 \%)$ or on ATG in $90(43 \%)$ of the patients, respectively, in association with calcineurin inhibitors and mycophenolate mofetil (patient characteristics according to GVHD prophylaxis were shown in Additional file 1: Table S1). Among patients receiving an ATG-based GVHD prophylaxis details on the type of ATG was available for 66 patients (27 received Thymoglobulin and 44 Fresenius). According to the type of ATG, the median dose of ATG was $10 \mathrm{mg} / \mathrm{Kg}$ (total dose) for the thymoglobulin and $30 \mathrm{mg} / \mathrm{Kg}$ (total dose) for the Fresenius.

Stem cell source was peripheral blood (PB) or bone marrow (BM) in 119 (57\%) and 89 (43\%) patients, respectively, (Table 1).

\section{Engraftment and graft-versus-host-disease}

Neutrophil engraftment was achieved in $92 \%$ of the patients. Median time to engraftment was 17 (range, 5-47) days. Seventeen patients (8.5\%) experienced graft failure. The 100-day cumulative incidence (CI) of grade II-IV aGvHD was $30.6 \%$ (95\% CI 24.3-37) (Fig. 1a) and $11 \%$ (95\% CI 7.1-15.8) for grades III-IV, respectively.

In univariate analysis, the 100-day CI of grade II-IV aGvHD was different according to the stem cell source, being $17.3 \%$ (95\% CI 10.2-26) for BM vs $40.8 \%$ (95\% CI 31.6-49.7) for PB, grafts $(p<0.01)$.

Similarly, in the multivariate analysis (Table 2), the use of $\mathrm{PB}$ was significantly associated with an increased risk of aGVHD (HR 3.00, 95\% CI 1.35-6.07, $p<0.01$ ) compared to BM (Additional file 2: Figure S1). RIC conditioning was associated with a reduced risk of aGVHD as well (HR 0.46, 95\% CI 0.23-0.93, $p=0.03$ ).

The 3-year CI of chronic GVHD was 29\% (Fig. 1b), and $\mathrm{CI}$ of extensive cGVHD was $10 \%$. No factors were significantly associated with cGVHD in the multivariate analysis (Table 2).

\section{Relapse incidence and non-relapse mortality}

The 3-year CI of relapse was 37\% (Fig. 1c), being $24 \%$ in patients in CR1, 32\% for those in CR2+, and $60 \%$ in patients with advanced disease at transplantation $(p<0.01)$.

The impact of disease status remained significant in multivariate analysis (advanced HR 8.04, 95\% CI 3.7617.19, $p<0.01$ ) and also the combination of female donor/male recipient was associated with a decreased risk of relapse in the multivariate analysis (HR 0.39, 95\% CI 0.18-0.84, $p=0.01$ ) (Table 2). 
Table 1 Patients, disease, and transplant characteristics

\begin{tabular}{|c|c|c|}
\hline \multicolumn{3}{|l|}{ Variables } \\
\hline Follow-up (months) & Median (range) & $31(2-79)$ \\
\hline Patient age (years) & Median (range) & $32(18-76)$ \\
\hline Year of Tx & Median (range) & $2012(2007-2014)$ \\
\hline \multirow[t]{2}{*}{ Patient sex } & Female & $80(39 \%)$ \\
\hline & Male & $127(61 \%)$ \\
\hline Karnofsky at Tx & $\geq 90 \%$ & $128(69 \%)$ \\
\hline Previous autologous Tx & Yes & $14(7 \%)$ \\
\hline \multirow[t]{3}{*}{ Disease status at $T x$} & CR1 & $91(44 \%)$ \\
\hline & CR2+ & $58(28 \%)$ \\
\hline & Advanced disease & $59(28 \%)$ \\
\hline \multirow[t]{2}{*}{ Immunophenotype } & B ALL & $100(66 \%)$ \\
\hline & TALL & $51(34 \%)$ \\
\hline CNS involvement & Yes & $10(10 \%)$ \\
\hline \multirow[t]{2}{*}{ Status of MRD at Tx } & Positive & 45 (49\%) \\
\hline & Negative & $46(51 \%)$ \\
\hline \multirow[t]{7}{*}{ Cytogenetics } & Ph-positive & $46(32 \%)$ \\
\hline & Ph-negative & $96(68 \%)$ \\
\hline & Normal karyotype & 37 \\
\hline & Abnormal karyotype & 32 \\
\hline & $t(4 ; 11)$ & 4 \\
\hline & $t(1 ; 19)$ & 5 \\
\hline & $t(12 ; 21)$ & 2 \\
\hline Donor age & Median (range) & $39(12-74)$ \\
\hline F donor/M recipient & Yes & $63(30 \%)$ \\
\hline \multirow[t]{2}{*}{ Stem cell source } & $\mathrm{BM}$ & $89(43 \%)$ \\
\hline & PB & $119(57 \%)$ \\
\hline \multirow[t]{4}{*}{ CMV D/R } & Neg to neg & $24(12 \%)$ \\
\hline & Pos to neg & $20(10 \%)$ \\
\hline & Neg to pos & $30(15 \%)$ \\
\hline & Pos to pos & $127(63 \%)$ \\
\hline \multirow[t]{4}{*}{ Donor kinship } & Parents & 49 (37\%) \\
\hline & Sibling & $51(38 \%)$ \\
\hline & Child & $25(19 \%)$ \\
\hline & Others relatives & $8(6 \%)$ \\
\hline \multirow[t]{10}{*}{ Conditioning regimen } & MAC & $137(66 \%)$ \\
\hline & TBI-based (8-12 Gy) & 63 \\
\hline & Cy TBI & 29 \\
\hline & Flu TBI & 31 \\
\hline & Other TBI & 3 \\
\hline & Chemo-based & 74 \\
\hline & TBF & 38 \\
\hline & $B u C y$ & 1 \\
\hline & Bu Flu & 3 \\
\hline & Flu Mel & 2 \\
\hline
\end{tabular}

Table 1 Patients, disease, and transplant characteristics (Continued)

\begin{tabular}{|c|c|c|}
\hline & Treo-based & 5 \\
\hline & Cy Flu & 5 \\
\hline & Cy AraC Bu & 19 \\
\hline & Cy Ida & 1 \\
\hline & $\mathrm{RIC}$ & $71(34 \%)$ \\
\hline & TBI based (<6 Gy) & 26 \\
\hline & Cy TBI & 15 \\
\hline & Flu TBI & 11 \\
\hline & Chemo-based & 45 \\
\hline & TBF & 8 \\
\hline & Bu Flu & 4 \\
\hline & $B u \pm$ others & 1 \\
\hline & Flu Mel & 6 \\
\hline & Bu Mel & 1 \\
\hline & Treo-based & 11 \\
\hline & Cy Flu & 11 \\
\hline & Cy thiotepa Bu & 1 \\
\hline & Cy AraC Bu & 1 \\
\hline GVHD prophylaxis & PT-Cy & 118 (57\%) \\
\hline & ATG-based & $90(43 \%)$ \\
\hline $\begin{array}{l}\text { Abbreviations: } T x \text { tran } \\
\text { leukemia, } M R D \text { minim } \\
\text { system, } F \text { female, } M \text { m } \\
\text { recipient, neg negative } \\
\text { irradiation, } C y \text { cyclor } \\
\text { fludarabine, Bu busulp } \\
\text { idarubicine, } R I C \text { reduc } \\
\text { PT-Cy post transplant } \\
\text { In Italics: details of cy }\end{array}$ & $\begin{array}{l}\text {, CR complete remissio } \\
\text { disease, } P \text { Philadelphic } \\
\text { ipheral blood, BM bone } \\
\text { ive, } M A C \text { myeloablative } \\
\text { ide, Flu fludarabine, } \\
\text { nelphalan, Treo treosu } \\
\text { y conditioning, GVHD } \\
\text { phamide, } A T G \text { anti-thy } \\
\text { s ph negative patient }\end{array}$ & $\begin{array}{l}\text { acute lymphoblastic } \\
\text { central nervous } \\
\text { w, } D \text { donor, } R \\
\text { ioning, } T B I \text { total body } \\
\text { hiotepa, busulphan } \\
\text { AraC cytarabine, Ida } \\
\text { ersus-host-disease, } \\
\text { e globulin } \\
\text { Eonditioning details }\end{array}$ \\
\hline
\end{tabular}

CI of NRM at 3 years was 32\% (Fig. 1d). NRM was not influenced by disease status at haplo-SCT; it was $29 \%$ in CR1, $36 \%$ in CR2+, and $34 \%$ in patients with advanced disease, respectively, $(p=0.59)$. One hundred thirty-five patients died, 42 (31\%) due to disease recurrence and 93 (69\%) from NRM

Forty-eight (52\%) patients died from infection, 24 (26\%) from GVHD, 4 (5\%) from hemorrhage, $1(1 \%)$ from cardiac toxicity, 2 (2\%) from sinusoidal obstruction syndrome (SOS), 3 (3\%) from interstitial pneumonia, 6 (6\%) from other transplant-related causes and 5 (5\%) missing (Additional file 3: Table S2). In the multivariate analysis (Table 2), the risk of NRM was significantly lower in patients with a Karnofsky performance status $\geq 90 \%$ (HR $0.23,95 \%$ CI $0.11-0.52, p<0.01$ ). The use of $\mathrm{PB}$ was associated with an increased risk of NRM (HR 2.56, 95\% CI 1.14-5.74, $p=0.02$ ).

\section{OS, LFS, and GRFS}

With a median follow-up of 31 months, the probability of 3-year OS, LFS, and GRFS was 33, 31, and 26\%, respectively. 


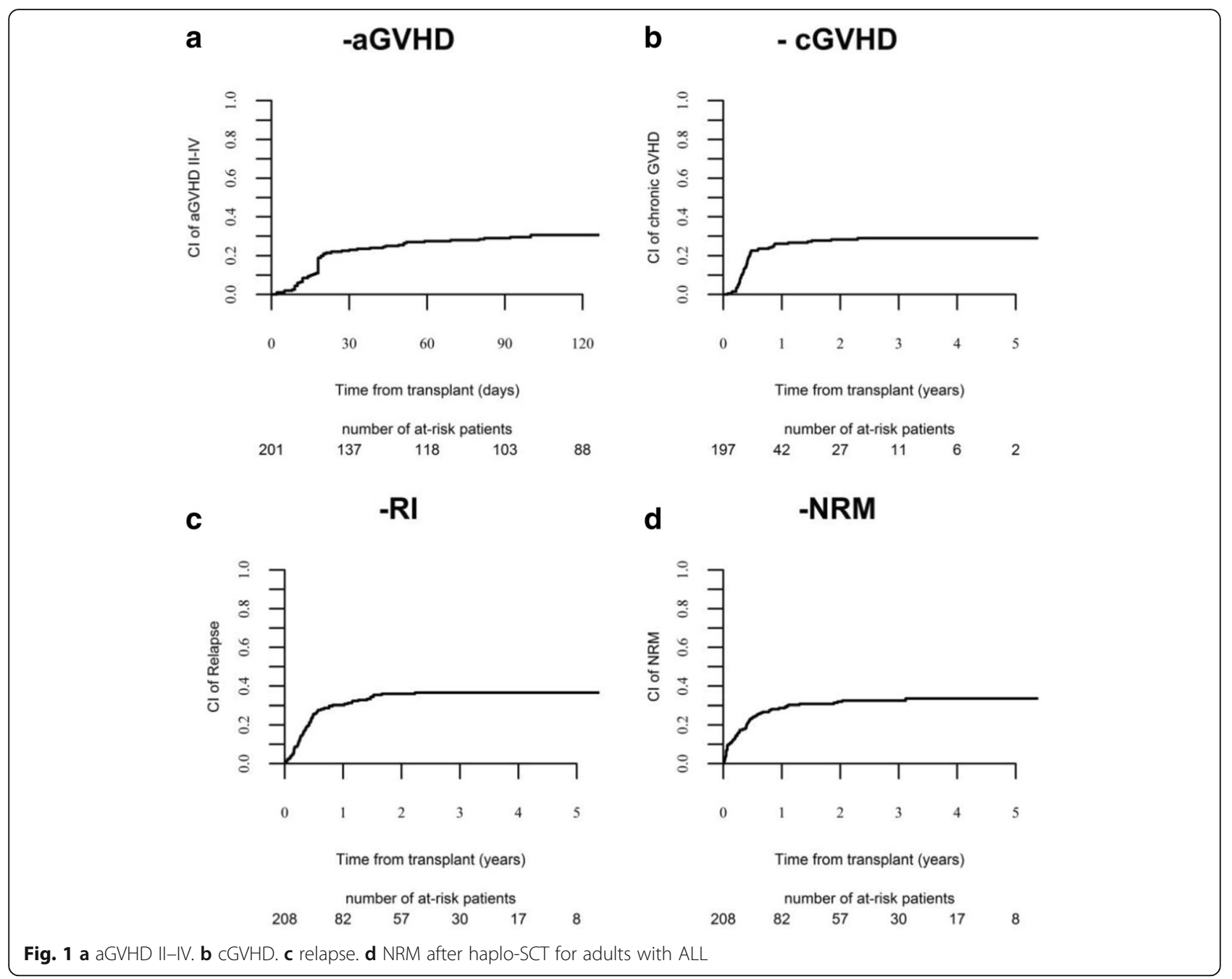

OS, LFS, and GRFS were significantly different according to disease status: OS was $52 \%$ in CR1, 34\% in CR2+, and $4 \%$ in advanced disease $(p<0.01)$; LFS was 47,33 , and $5(p<0.01)$; and GRFS was 41,24 , and $5(p<0.01)$, respectively, (Fig. 2a-c).

Figure 3 shows OS and LFS according to the type of GVHD prophylaxis.

In the multivariate analysis (Table 2), disease status and the use of $\mathrm{PB}$ as stem cell source were found as negative prognostic factors for OS (CR2+ vs CR1: HR 2.22, 95\% CI 1.22-4.03, $p<0.01$; advanced vs CR1: HR 3.66, 95\% CI 2.06-6.52, $p<0.01$; PB vs BM: HR 1.98, 95\% CI 1.14-3.42, $p<0.01$ ), for LFS (CR2+ vs CR1: HR 1.91, 95\% CI 1.06-3.41, $p=0.02$; advanced vs CR1: HR 3.81, 95\% CI 2.17-6.67, $p<0.01$; PB vs BM: HR 1.81, 95\% CI 1.06-3.09, $p=0.02$ ) and for GRFS (advanced vs CR1: HR 2.71, 95\% CI 1.56-4.68, $p<0.01$; PB vs BM: HR $1.82,95 \%$ CI $1.10-3.01, p=0.01)$.

\section{Discussion}

Allo-SCT remains the most effective post-remission treatment for adults with ALL and is the standard of care in high-risk patients including those with persistent or relapsing MRD, steroid and/or chemotherapyresistance, and experiencing relapse after initial CR [9]. Several studies reported a 5-year LFS ranging from 40 to $60 \%$ in patients in CR1 receiving allogenic transplantation from an HLA-matched sibling or MUD [10-12]. Improvement of results over time has recently been reported [33].

Unfortunately, for a significant proportion of patients, an HLA identical donor cannot be identified leaving room for alternative approaches, such as transplantations from either mismatched unrelated or haploidentical donors. Thanks to easy access to haploidentical donors and to the introduction of innovative technologies, the procedure may be organized fast, avoiding delay 
Table 2 Multivariate analysis for outcomes

\begin{tabular}{llll}
\hline & HR & Cl & $p$ \\
\hline & Relapse & & \\
Age (per 10 years) & 0.95 & $0.744-1.217$ & 0.69 \\
Status at Tx & & & \\
CR1 (reference) & 1 & & \\
CR2+ & 1.69 & $0.72-3.95$ & 0.22 \\
Advanced & 8.04 & $3.76-17.19$ & $<0.01$ \\
Ph+ vs Ph- & 1.09 & $0.53-2.24$ & 0.80 \\
KPS $\geq 90 \%$ & 2.02 & $0.95-4.29$ & 0.06 \\
Female recipient & 0.59 & $0.29-1.20$ & 0.14 \\
Female D $\geq$ male R & 0.39 & $0.18-0.84$ & 0.01 \\
RIC vs MAC & 1.32 & $0.67-2.5$ & 0.41 \\
R CMV positive & 1.11 & $0.45-2.75$ & 0.81 \\
ATG vs PT-Cy & 1.15 & $0.63-2.13$ & 0.63 \\
PB vs BM & 1.46 & $0.68-3.10$ & 0.32 \\
Center (frailty) & & & 0.94 \\
& & &
\end{tabular}

$\begin{array}{ll}\text { Age (per } 10 \text { years) } & \text { NRM } \\ \text { Status at Tx } & 0.98\end{array}$

$$
0.72-1.33
$$$$
0.90
$$

CR1 (reference) 1

$\begin{array}{ll}\text { CR2+ } & 2.15 \\ \text { Advanced } & 1.50 \\ \text { Ph+ vs Ph- } & 1.45 \\ \text { KPS } \geq 90 \% & 0.23 \\ \text { Female recipient } & 1.26 \\ \text { Female D } \geq \text { male R } & 1.47 \\ \text { RIC vs MAC } & 0.76 \\ \text { R CMV positive } & 0.57 \\ \text { ATG vs PT-Cy } & 1.79 \\ \text { PB vs BM } & 2.56 \\ \text { Center (frailty) } & \end{array}$

LFS

Age (per 10 years) $\quad 0.98$

Status at Tx

CR1 (reference)

$\begin{array}{llll}\text { CR2+ } & 1.91 & 1.06-3.41 & 0.02 \\ \text { Advanced } & 3.81 & 2.17-6.67 & <0.01 \\ \text { Ph + vs Ph- } & 1.13 & 0.66-1.94 & 0.63 \\ \text { KPS } \geq 90 \% & 0.78 & 0.47-1.29 & 0.34 \\ \text { Female recipient } & 0.77 & 0.45-1.32 & 0.35 \\ \text { Female D } \geq \text { male R } & 0.72 & 0.41-1.24 & 0.24 \\ \text { RIC vs MAC } & 1.05 & 0.64-1.72 & 0.82 \\ \text { R CMV positive } & 0.73 & 0.40-1.33 & 0.31 \\ \text { ATG vs PT-Cy } & 1.32 & 0.84-2.06 & 0.21 \\ \text { PB vs BM } & 1.81 & 1.06-3.09 & 0.02\end{array}$

$0.92-5.02 \quad 0.07$

0.59-3.82

$0.61-3.42$

$0.10-0.52$

0.52-3.04

0.60-3.57

0.36-1.60

0.23-1.41

0.90-3.55

$1.14-5.74$

0.39

0.39

$<0.01$

0.59

0.39

0.47

0.22

0.09

0.02

0.94
Table 2 Multivariate analysis for outcomes (Continued)

\begin{tabular}{llll}
\hline Center (frailty) & & & 0.9 \\
& OS & & \\
Age (per 10 years) & 1.02 & $0.84-1.22$ & 0.82 \\
Status at Tx & & & \\
CR1 (reference) & 1 & & \\
CR2+ & 2.22 & $1.22-4.03$ & $<0.01$ \\
Advanced & 3.66 & $2.06-6.52$ & $<0.01$ \\
Ph + vs Ph- & 1.16 & $0.67-2.01$ & 0.58 \\
KPS $\geq 90 \%$ & 0.62 & $0.37-1.02$ & 0.06 \\
Female recipient & 0.81 & $0.47-1.38$ & 0.44 \\
Female D $\geq$ male R & 0.76 & $0.43-1.35$ & 0.36 \\
RIC vs MAC & 0.91 & $0.56-1.48$ & 0.71 \\
R CMV positive & 0.81 & $0.43-1.51$ & 0.51 \\
ATG vs PT-Cy & 1.4 & $0.88-2.20$ & 0.14 \\
PB vs BM & 1.98 & $1.14-3.42$ & 0.01 \\
Center (frailty) & & & 0.92
\end{tabular}

Age (per 10 years)

GRFS

Status at TX

CR1 (reference)

CR2+

Advanced

$\mathrm{Ph}+\mathrm{vs} \mathrm{Ph}-$

KPS $\geq 90 \%$

Female recipient

Female $D \geq$ male $R$

0.91

$0.76-1.08$

0.29

RIC VS MAC

R CMV positive

ATG vs PT-Cy

$P B$ vs BM

Center (frailty)

$0.78-2.34 \quad 0.28$

1.35

2.71

1.56-4.68

0.28

1.20

$0.72-2.02$

$<0.01$

0.47

0.84

0.50-1.40

0.51

0.70

$0.42-1.18$

0.18

0.81

$0.48-1.38$

0.45

1.03

0.65-1.63

0.87

0.85

$0.47-1.53$

0.59

1.04

0.67-1.61

0.85

1.82

$1.10-3.01$

0.01

0.92

aGVHD II-IV

Age (per 10 years)

0.75

$0.56-1.00$

0.05

Status at Tx

CR1 (reference)

CR2+

Advanced

1.45

0.76

0.696-3.024

0.32

$\mathrm{Ph}+\mathrm{vs} \mathrm{Ph}-$

$0.29-2.0$

0.59

KPS $\geq 90 \%$

1.15

$0.52-2.55$

0.72

Female recipient

0.80

0.33-1.93

0.63

Female $D \geq$ male $R$

1.23

$0.53-2.88$

0.62

RIC vs MAC

R CMV positive

$0.82-4.13$

0.13

1.84

0.23-0.93

0.03

ATG vs PT-Cy

0.43-3.78

0.65

1.28

0.97

$0.52-1.81$

0.93

$P B$ vs BM

3.00

$1.35-6.70$

$<0.01$ 
Table 2 Multivariate analysis for outcomes (Continued)

\begin{tabular}{llll}
\hline Center (frailty) & & & 0.93 \\
& CGVHD & & \\
Age (per 10 years) & 0.97 & $0.69-1.37$ & 0.89 \\
Status at Tx & & & \\
CR1 (reference) & 1 & & \\
CR2+ & 0.58 & $0.20-1.71$ & 0.33 \\
Advanced & 0.62 & $0.20-1.90$ & 0.40 \\
Ph + vs Ph- & 0.86 & $0.33-2.20$ & 0.75 \\
KPS 90\% & 0.68 & $0.26-1.77$ & 0.43 \\
Female recipient & 0.93 & $0.34-2.57$ & 0.90 \\
Female D $\geq$ male R & 1.38 & $0.48-3.94$ & 0.54 \\
RIC vs MAC & 0.94 & $0.38-2.36$ & 0.91 \\
R CMV positive & 0.51 & $0.16-1.56$ & 0.24 \\
ATG vs PT-Cy & 0.67 & $0.25-1.73$ & 0.41 \\
PB vs BM & 1.98 & $0.76-5.14$ & 0.15 \\
Center (frailty) & & & 0.13
\end{tabular}

Abbreviations: $R /$ relapse incidence, NRM non-relapse mortality, LFS leukemia-free survival, OS overall survival, GRFS refined graft-versus-host-free, relapse-free survival, $a G V H D$ acute GVHD, cGVHD chronic GVHD, Tx transplantation, $C R$ complete remission, Ph Philadelphia, KPS Karnofsky performance status, $D$ donor, $R$ recipient, $M A C$ myeloablative conditioning, $R / C$ reduced intensity conditioning, ATG anti-thymocyte globulin, $P T$-Cy post-transplant cyclophosphamide, $P B$ peripheral blood, $B M$ bone marrow

In Italics: details of cytogenetics ph negative patients and conditioning details

caused by the search of unrelated donor. The attractiveness of haplo-SCT should be verified by detailed analysis of results, as potential advantages may be counterbalanced by increased risk of immune-related complications. As well, the impact on the incidence of relapse remains unknown and may vary according to diagnosis and disease status. Hence, there is need for studies focusing on homogenous populations in terms of the diagnosis. In the current one, the analysis was performed on adults with ALL, the area that has never been extensively explored.

In the largest report so far, Srour et al. [26] included 109 adults with ALL treated with haplo-SCT with GVHD prophylaxis uniformly based on PT-Cy. Only 32 patients were treated in CR1, and estimated 3-year LFS in this subgroup was 52\%. The results of our study including 208 patients (44\% in CR1) correspond well with the previous ones confirming the feasibility and efficacy of the procedure in this high-risk disease. However, in contrast to the study by Srour et al., we report results of two types of immunosuppressive regimen in the haplo-SCT setting. In our series, we did not find any difference in the outcome according to the type of GVHD prophylaxis except for a trend to increased risk of NRM in ATG group. This effect, however, did not reach statistical significance. Therefore, for adults with ALL in the haplo-SCT setting, both types of GVHD prophylaxis may be successfully used by transplant centers according to their policy.
As expected, disease status was the most important prognostic factor affecting relapse and survival. While the outcome of patients treated in CR1 appears comparable to results reported for HLA matched SCT in corresponding period [33], results of those with active disease remain very poor with only $5 \%$ OS reported at 3 years. Pavlu et al. recently reported results of HLA-matched SCT for patients with primary refractory ALL. The probability of LFS at 2 years was 28\% [34]. However, in the setting of haplo-SCT results for patients with advanced disease status remain poor and efforts to achieve disease remission before transplant are needed. Modern approaches including bi-specific $\mathrm{T}$ cell engaging antibodies (blinatumomab) [35] or anti-CD22 immunoconjugates (inotuzumab ozogamycin) [36] have become available allowing a significant proportion of relapsed/refractory patients being bridged to SCT. As well, the use of chimeric antigen receptor (CAR) $\mathrm{T}$ cells [37, 38] is emerging as an effective approach for patients with lymphoid malignancies resistant to conventional chemotherapy.

In the study by Pavlu et al., [34] the outcome of patients with refractory disease was affected by the type of conditioning and donor/recipient-gender combination (better results for female donor to male recipient). In the current study, neither the type nor intensity of the conditioning had impact on outcome. This is consistent by previous findings by our group in the setting of unmanipulated haplo-SCT [39].

In our study, transplants from female donor to male recipient were associated with significantly reduced risk of relapse, without major impact on NRM and other outcomes. This observation suggests that ALL is particularly susceptible to graft-versus-leukemia reaction associated with mismatches of minor histocompatibility antigen encoded on Y chromosome.

Two retrospective studies comparing the type of stem cell source for haplo-SCT with PT-Cy were published showing no difference in terms of the incidence of GVHD and survival [40, 41]. Both analyses included RIC transplants and the populations with various myeloid and lymphoid malignancies. In contrast to the abovecited reports, the results of our study indicate a strong impact of the source of stem cells on outcome of unmanipulated haplo-SCT for adults with ALL. The use of PB was associated with significantly increased risk of acute GVHD and NRM, which translated into decreased survival, and leukemia-free survival. It must be stressed, however, that our population included both MAC and RIC procedures and different GVHD prophylaxis. The interaction between these variables and the effect of stem cell source on outcome should be considered and requires further exploration. With the rapid increase of unmanipulated haplo-SCT in the recent era the matter 
a
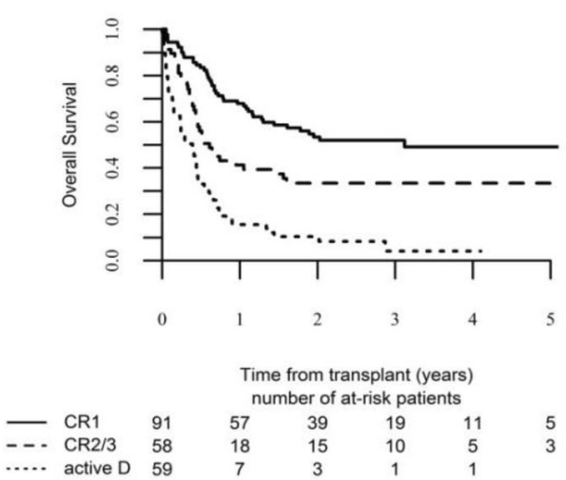

C

- GRFS

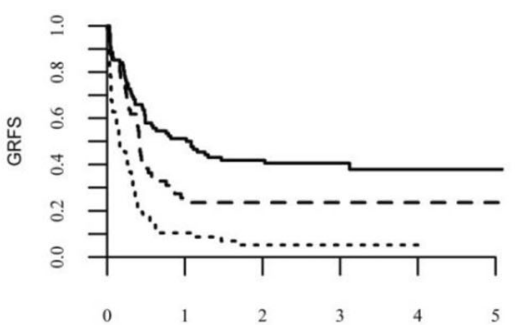

Time from transplant (years)

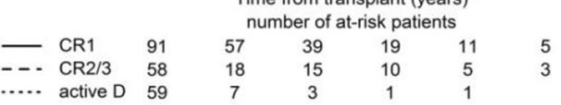

\section{b - - LFS}

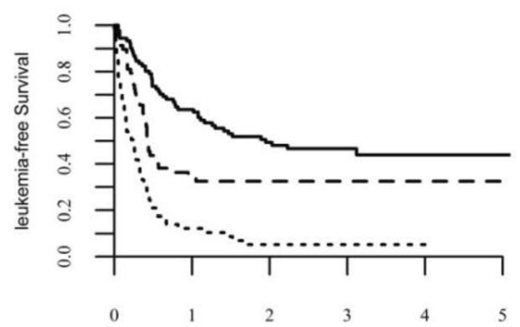

Time from transplant (years)

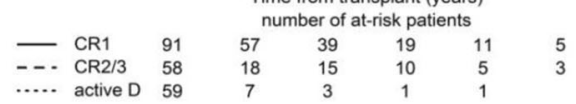

Fig. 2 a OS. b LFS. c GRFS after haplo-SCT for adults with ALL according to disease status

of optimal stem cell source needs to be addressed in larger homogenous population.

We are aware that in our study, there may be unmeasured factors that have not been considered, and this is a limitation when conducting retrospective studies. Some important data on cytogenetics and MRD are lacking, and also, the choice of the intensity and type of conditioning regimen, GVHD prophylaxis, and stem cell source are done according to each centers' protocols and experience. Furthermore, the population of our study was homogenous in terms of the diagnosis, but ALL itself is a heterogeneous disease. In particular, a

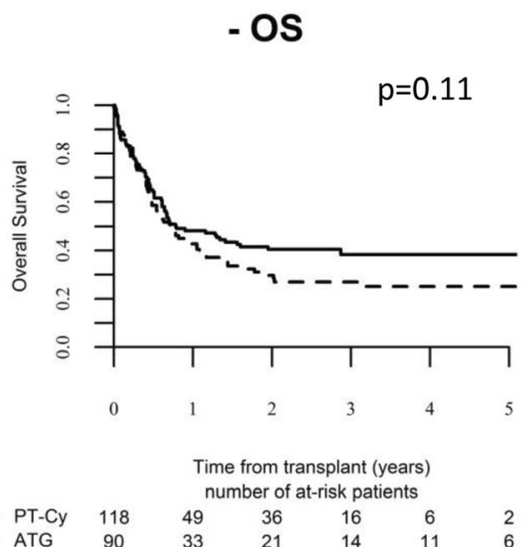

b

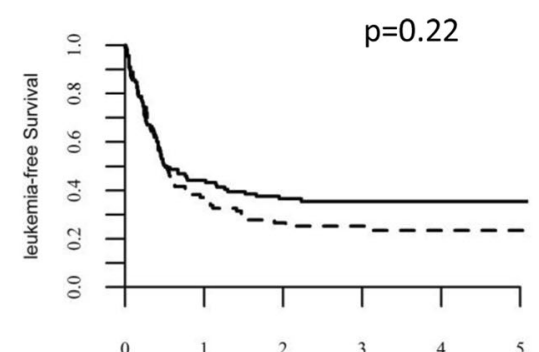

Time from transplant (years) number of at-risk patients

$\begin{array}{llccc}49 & 36 & 16 & 6 & 2 \\ 33 & 21 & 14 & 11 & 6\end{array}$

Fig. 3 a OS. b LFS after haplo according to GVHD prophylaxis 
treatment protocols differ for patients with Ph-positive and Ph-negative disease. Tyrosine kinase inhibitors are widely implemented in up-front treatment of Ph-positive ALL, but their use is also recommended in post-alloSCT prophylaxis, which may influence the final outcome [42]. The retrospective nature of our study did not allow including this variable in the analysis. As well, data on minimal residual disease, being the most important prognostic factor in Ph-negative ALL, were unavailable [43].

\section{Conclusions}

Despite above limitations, our results suggest that unmanipulated haplo-SCT is a valuable treatment option for adults with ALL with the great advantage of being able to quickly find a donor and avoid the risk of early relapse. Prospective studies are needed to compare the results of haplo-SCT with other types of donor on an intention-to-treat basis.

\section{Additional files}

Additional file 1: Table S1. Patient characteristics according to GVHD prophylaxis. (DOCX $19 \mathrm{~kb}$ )

Additional file 2: Figure S1. Acute and chronic GVHD according to stem cell source. (DOCX $104 \mathrm{~kb}$ )

Additional file 3: Table S2. Causes of death according to GVHD prophylaxis. (DOCX $17 \mathrm{~kb})$

\section{Abbreviations \\ A: Acute; ALL: Acute lymphoblastic leukemia; allo-SCT: Allogenic hematopoietic stem cell transplantation; ATG: Anti-thymocyte globulin; BM: Bone marrow; Bu: Busulfan; C: Chronic; CAR: Chimeric antigen receptor; Cl: Cumulative incidence; CR: Complete remission; DLIs: Donations or donor lymphocyte infusions; GRFS: GVHD-free, relapse-free-survival; GVHD: Graft-versus-host- disease; haplo-SCT: Haploidentical allo-SCT; KPS: Karnofsky performance status; LFS: Leukemia-free survival; MAC: Myeloablative conditioning; MRD: Minimal residual disease; MUD: Matched unrelated donor; NRM: Non-relapse mortality; OS: Overall survival; PB: Peripheral blood; PCR: Polymerase chain reaction; PT- Cy: Post-transplant cyclophosphamide; RI: Relapse incidence; RIC: Reduced intensity regimen; TBF: Thiotepa, busulphan, fludarabine; TBI: Total body irradiation; TCD: T cell depleted; TKl: Tyrosine kinase inhibitors}

\section{Acknowledgements}

Authors thank Audrey Mailhol and Emmanuelle Polge for helping in data collection.

Participating centers: Ospedale San Martino, Department of Haematology II, Genova, Italy; Ospedale San Raffaele s.r.l., Haematology and BMT, Milano, Italy; Anadolu Medical Center Hospital, Bone Marrow Transplantation Department, Kocaeli, Turkey; Bone Marrow Transplantation Center, The First Affiliated Hospital, Zhejiang University School of Medicine, Hangzhou, China; First State Pavlov Medical University of St. Petersburg, Raisa Gorbacheva Memorial Research Institute for Paediatric Oncology, Hematology, and Transplantation, St. Petersburg, Russia; Tor Vergata University of Rome, Stem Cell Transplant Unit, Policlinico Universitario, Rome, Italy; First Affiliated Hospital of Soochow University, Department of Hematology, China; Medical Park Hospitals, Stem Cell Transplant Unit, Lara, Antalya, Turkey; Klinikum Grosshadern, Med. Klinik III, Munich, Germany; Ospedale Civile, Dipartimento di Ematologia, Medicina Trasfusionale e Biotecnologie, Pescara, Italy; Hôpitaux Universitaires de Genève, Département des Spécialités de Médecine, Service d'Hématologie, Geneva, Switzerland; Hospital Gregorio Marañón, Sección de Trasplante de Medula Osea, Madrid, Spain; Hospital Guglielmo da Saliceto, Oncology and Hematology Department, Piacenza, Italy; Ospedale S. Camillo-
Forlanini, Department of Hematology and BMT, Rome, Italy; European Institute of Oncology, Institute of Haematology, Milano, Italy; U.O.D Trapianti di midollo osseo, A.O.R Villa Sofia-Cervello, Palermo, Italy; Azienda Ospedaliera, Centro Unico Regionale Trapianti, Alberto Neri, Bianchi-Melacrino-Morelli, Reggio Calabria, Italy; Baskent University Hospital, Haematology Division, BMT Unit, Haemaology Reserach Laboratory, Training \& Medical, Adana, Turkey; CHU Nantes, Department D’Hematologie, Nantes, France; Fundación Jiménez Díaz, Hematología, Madrid, Spain; King Faisal Specialist Hospital \& Research Centre, Oncology (Section of Adult Haematolgy/BMT), Riyadh, Saudi Arabia; University of Cologne, I. Department of Medicine, Cologne, Germany; Ospedale San Gerardo, Clinica Ematologica dell'Universita Milano-Biocca, Monza, Italy; Klinkum Rechts der Isar, III Med Klinik der TU, Munich, Germany; University of Napoli, 'Federico II' Medical School, Division of Hematology, Napoli, Italy; Hopital Saint Antoine, Department of Hematology, Paris, France; Azienda Ospedali Riuniti di Ancona, Department of Hematology, Ancona University, Ancona, Italy; Adult and Paediatric Transplant Centre, Centro Trapianti di Midollo Osseo, Cagliari, Italy; Private Medicana International Ankara Hospital, Dept. Bone Marrow Transplantation, Ankara, Turkey; Universitätsmedizin Mannheim, III. Medizinische Klinik, Einheit für Stammzelltransplantation, Theodor-Kutz, Mannheim, Germany; University Hospital, Hematology, Basel, Switzerland; Imperial College, Department of Haematology, Hammersmith Hospital, London, UK; University Hospital Gasthuisberg, Department of Hematology, Leuven, Belgium; Hospital Clinic, Institute of Hematology \& Oncology, Department of Hematology, Barcelona, Spain; Universität Tübingen, Medizinische Klinik, Abteilung II, Tübingen,

Germany; S.S.C.V.D Trapianto di Cellule Staminali, A.O.U Citta della Salute e della Scienza di Torino, Torino, Italy; Hopital Jean Minjoz, Service d'Hématologie, Besancon, France; Hosp. Reina Sofia, Córdoba Hospital, Department of Hematology, Córdoba, Spain; Hospital Clínico Universitario, Servicio de Hematología, Valencia, Spain; Ospedale di Niguarda Ca' Granda, Hematology Department, Milano, Italy; University Hospital Center Rebro, Zagreb, Croatia; Azienda Ospedaliera Universitaria Careggi, BMT Unit Department of Hematology, Firenze, Italy; Universita Cattolica S. Cuore, Istituto di Ematologia, Rome, Italy; U.O.S.A Centro Trapianti e Terapia Cellulare, Azienda Ospedaliera Universitaria Senese, Policlinico S.Maria alle Scotte, Siena, Italy; ZNA, Antwerp, Belgium; Specialized Children's Oncohematology Hospital, Sofia, Bulgaria; Istituto Clinico Humanitas, Transplantation Unit, Department of Oncology and Haematology, Milano, Italy; Beilinson Hospital, Hematology and BMT Department, Petach-Tikva, Israel; Fondazione IRCCS Policlinico San Matteo, Pediatric Hematology-Oncology, Pavia, Italy; George Papanicolaou General Hospital, Haematology Department/BMT Unit, Thessaloniki, Greece; Clinic of Hematology, Military Medical Academy, Belgrade, Serbia and Montenegro; Hospital Vall d'Hebron, Unidad de Adultos, Barcelona, Spain; Hospital Universitario Donostia, San Sebastian, Spain; University Hospital Eppendorf, Bone Marrow Transplantation Centre, Hamburg, Germany; Ankara University Faculty of Medicine, Department of Hematology, Adult Stem Cell Transplantation Unit, Dikimevi, Ankara, Turkey; Shariati Hospital, Hematology-Oncology and BMT Research, Teheran, Iran; Hospital Universitario Central de Asturias, Oviedo, Spain; U.O. Ematologia con Trapianto, Azienda Ospedaliero Universitaria Policlinico Bari, Bari, Italy; Azienda Ospedaliera Papa Giovanni XXIII, Hematology and Bone Marrow Transplant Unit, Bergamo, Italy; Centre Hospitalier Lyon Sud, Service Hematologie, Lyon, France; Ospedale La Maddalena - Dpt. Oncologico, Unità Operativa di Oncoematologia e, Trapianto di Midollo, Palermo, Italy; Centre Pierre et Marie Curie, Service Hématologie Greffe de Moëlle, Alger, Algeria; Universitätsklinikum Würzburg, Med. Klinik und Poliklinik II, Würzburg, Germany; Umea University Hospital, Hematology, Umeå, Sweden; Hospital Morales Meseguer, Unidad de Trasplante de Médula Osea, Serv de Hemat, Murcia, Spain; A.O.R.N. 'SAN.G MOSCATI', Ematologia, Avellino, Italy; Unità Operativa Oncoematologia Pediatrica, Azienda Ospedaliera Universitaria Pisa, Pisa, Italy; and Florence Nightingale Sisli Hospital, Hematopoietic SCT Unit, Istanbul, Turkey.

\section{Funding}

Not applicable.

\section{Availability of data and materials}

The dataset supporting the conclusions of this article are available in the ALWP of EBMT in Paris, 184 rue Faubourg Saint Antoine.

\section{Authors' contributions}

$A R, M L$, and $A N$ designed the study. NS and $A R$ wrote the manuscript. $M L$ performed the statistical analysis. AB, FC, ZG, HH, BA, WA, WD, YC, JT, SS, SG, and MM provided cases for the study. All authors edited and approved the manuscript. 


\section{Competing interests}

The authors declare that they have no competing interests.

\section{Consent for publication}

Not applicable.

\section{Ethics approval and consent to participate}

This study was approved by the ALWP of the EBMT institutional review board. The study was conducted in accordance with the Declaration of Helsinki and Good Clinical Practice guidelines. All patients or legal guardians provided written informed consent authorizing the use of their personal information for research purposes.

\section{Publisher's Note}

Springer Nature remains neutral with regard to jurisdictional claims in published maps and institutional affiliations.

\begin{abstract}
Author details
${ }^{1}$ Department of Hematology and Cell Therapy, Hôpital Saint-Antoine, 184 Rue du Faubourg Saint Antoine, 75012 Paris, France. ${ }^{2}$ Department of Medicine, Division of Hematology and Clinical Immunology, University of Perugia, Perugia, Italy. ${ }^{3}$ ALWP office, Hôpital Saint-Antoine, Paris, France. ${ }^{4}$ Department of Hematology II, Ospedale San Martino, Genova, Italy. ${ }^{5}$ Università cattolica del Sacro Cuore, Roma, Italy. ${ }^{6} \mathrm{Hematology}$ and Bone Marrow Transplantation Unit, IRCCS San Raffaele Scientific Institute, Milan, Italy. ${ }^{7}$ Hematology Department, Anadolu Medical Center Hospital, Kocaeli, Turkey. ${ }^{8}$ Bone Marrow Transplantation Center, The First Affiliated Hospital, School of Medicine, Zhejiang University School of Medicine, Hangzhou, Zhejiang, China. ${ }^{9}$ Hematology and Transplantology, Ratsa Gorbacheva Memorial Children's Institute, Saint Petersburg State Medical Pavlov University, St. Petersburg, Russian Federation. ${ }^{10}$ Stem Cell Transplant Unit, Department of Hematology, Tor Vergata "University Hospital", Rome, Italy. ${ }^{11}$ Department of Hematology, The First Affiliated Hospital of Soochow University, Suzhou, Jiangsu, China. ${ }^{12}$ Stem Cell Transplant Unit, Medical Park Hospitals, Antalya, Turkey. ${ }^{13}$ Department of Internal Medicine III, Hematopoietic Stem Cell Transplantation, Ludwig-Maximilians-University Hospital of Munich-Grosshadern, Munich, Germany. ${ }^{14}$ Department of Hematology and Trasfusional Medicine, Lund University, Ospedale Civile, Pescara, Italy. ${ }^{15}$ Department of Bone Marrow Transplantation and Onco-Hematology, Comprehensive Cancer Center M. Sklodowska-Curie Memorial Institute, Gliwice Branch, Gliwice, Poland. ${ }^{16}$ Department of Hematology and Bone Marrow Transplantation, Chaim Sheba Medical Center, Tel Aviv, Israel.
\end{abstract}

\section{Received: 11 April 2017 Accepted: 19 May 2017}

\section{Published online: 30 May 2017}

\section{References}

1. Siegel RL, Miller KD, Jemal A. Cancer statistics 2016. CA Cancer J Clin. 2016; 66:7-30.

2. Inaba H, Greaves M, Mullighan CG. Acute lymphoblastic leukaemia. Lancet. 2013:381:1943-55.

3. Jabbour E, O'Brien S, Konopleva M, Kantarjian H. New insights into the pathophysiology and therapy of adult acute lymphoblastic leukemia. Cancer. 2015;121:2517-28.

4. Sive Jl, Buck G, Fielding A, Lazarus HM, Litzow MR, Luger S, Marks DI, McMillan A, Moorman AV, Richards SM, et al. Outcomes in older adults with acute lymphoblastic leukaemia (ALL): results from the international MRC UKALL XII/ ECOG 2993 trial. Br J Haematol. 2012;157:463-71.

5. Kantarjian HM, Thomas D, O'Brien S, Cortes J, Giles F, Jeha S, Bueso-Ramos CE, Pierce $S$, Shan J, Koller C, et al. Long-term follow-up results of hyperfractionated cyclophosphamide, vincristine, doxorubicin, and dexamethasone (hyper-CVAD), a dose-intensive regimen, in adult acute lymphocytic leukemia. Cancer. 2004;101:2788-801.

6. Gokbuget N, Stanze D, Beck J, Diedrich H, Horst HA, Hüttmann A, Kobbe G, Kreuzer KA, Leimer L, Reichle A, et al. Outcome of relapsed adult acute lymphoblastic leukemia depends on reponse to salvage chemotherapy, prognostic factors, and performance of stem cell transplantation. Blood. 2012;120:2032-41.

7. Goldstone AH, Richards SM, Lazarus HM, Tallman MS, Buck G, Fielding AK, Burnett AK, Chopra R, Wiernik PH, Foroni L, et al. In adults with standard-risk acute lymphoblastic leukemia, the greatest benefit is achieved from a matched sibling allogeneic transplantation in first complete remission, and an autologous transplantation is less effective than conventional consolidation/maintenance chemotherapy in all patients: final results of the International ALL Trial (MRC UKALL XII/ECOG E2993). Blood. 2008;111:1827-33.

8. Thomas X, Boiron JM, Huguet F, Dombret H, Bradstock K, Vey N, Kovacsovics T, Delannoy A, Fegueux N, Fenaux $P$, et al. Outcome of treatment in adults with acute lymphoblastic leukemia: analysis of the LALA-94 trial. J Clin Oncol. 2004; 22:4075-86.

9. Sureda A, Bader P, Cesaro S, Dreger P, Duarte RF, Dufour C, Falkenburg JH, Farge-Bancel D, Gennery A, Kröger N, et al. Indications for allo- and autoSCT for haematological diseases, solid tumours and immune disorders: current practice in Europe, 2015. Bone Marrow Transplant. 2015;50:1037-56.

10. Gupta V, Richards S, Rowe J, Acute Leukemia Stem Cell Transplantation Trialists' Collaborative Group. Allogeneic, but not autologous, hematopoietic cell transplantation improves survival only among younger adults with acute lymphoblastic leukemia in first remission: an individual patient data meta analysis. Blood. 2013;121:339-50.

11. Oliansky DM, Larson RA, Weisdorf D, Dillon H, Ratko TA, Wall D, McCarthy Jr $\mathrm{PL}$, Hahn T, et al. The role of cytotoxic therapy with hemopoietic stem cell transplantation in the treatment of adult acute lymphoblastic leukemia: update of the 2006 evidence based review. Biol Blood Marrow Transplant. 2012;18:18-36.

12. Messori A, Fadda V, Maratea D, Trippoli S. Acute lymphoblastic leukemia in first complete remission: temporal trend of outcomes in studies comparing allogenic transplant with autologus transplant or chemotherapy. Ann Hematol. 2013;92:1221-8.

13. Ciurea SO, Bayraktar UD. "No donor"? Consider a haploidentical transplant. Blood Rev. 2015;29:63-70.

14. Tucunduva L, Ruggeri A, Sanz G, Furst S, Socié G, Michallet M, Arcese W Milpied N, Yakoub-Agha I, Linkesch W, et al. Risk factors for outcomes after unrelated cord blood transplantation for adults with acute lymphoblastic leukemia: a report on behalf of Eurocord and the Acute Leukemia Working Party of the European Group for Blood and Marrow Transplantation. Bone Marrow Transplant. 2014;49:887-94.

15. Passweg JR, Baldomero H, Bader P, Bonini C, Cesaro S, Dreger P, Duarte RF, Dufour C, Falkenburg JH, Farge-Bancel D, et al. Hematopoietic SCT in Europe 2013: recent trends in the use of alternative donors showing more haploidentical donors but fewer cord blood transplants. Bone Marrow Transplant. 2015;50:476-82.

16. Kanakry CG, Fuchs EJ, Luznik L. Modern approaches to HLA-haploidentical blood or marrow transplantation. Nat Rev Clin Oncol. 2016;13:10-24.

17. Luznik L, O'Donnel PV, Fuchs EJ. Post transplantation cyclophosphamide for tolerance induction in HLA haploidentical BMT. Seminar Oncol. 2012;39:683-93.

18. Raiola AM, Dominietto A, Ghiso A, Di Grazia C, Lamparelli T, Gualandi F, Bregante S, Van Lint MT, Geroldi S, Luchetti S, et al. Unmanipulated haploidentical bone marrow transplantation and posttransplantation cyclophosphamide for hematologic malignancies after myeloablative conditioning. Biol Blood Marrow Transplant. 2013;19:117-22.

19. Di Bartolomeo P, Santarone S, De A, Picardi A, Cudillo L, Cerretti R, Adorno G, Angelini S, Andreani M, De Felice L, et al. Haploidentical, unmanipulated, G-CSF-primed bone marrow transplantation for patients with high-risk hematologic malignancies. Blood. 2013;121:849-57.

20. Wang Y, Liu QF, Xu LP, Liu KY, Zhang XH, Ma X, Wu MQ, Wu DP, Huang XJ. Haploidentical versus matched-sibling transplant in adults with Philadelphianegative high-risk acute lymphoblastic leukemia: a biologically phase III randomized study. Clin Cancer Res. 2016;22:3467-76.

21. Chang YJ, Huang XJ. Haploidentical stem cell transplantation: anti-thymocyte globulin-based experience. Semin Hematol. 2016;53:82-9.

22. Savani BN, Labopin M, Kröger N, Finke J, Ehninger G, Niederwieser D, Schwerdtfeger R, Bunjes D, Glass B, Socié G, et al. Expanding transplant options to patients over 50 years. Improved outcome after reduced intensity conditioning mismatchedunrelated donor transplantation for patients with acute myeloid leukemia: a report from the Acute Leukemia Working Party of the EBMT. Haematologica. 2016;101:773-80.

23. Piemontese S, Ciceri F, Labopin M, Bacigalupo A, Huang H, Santarone $\mathrm{S}$, Gorin NC, Koc Y, Wu D, Beelen D, et al. A survey of unmanipulated haploidentical hematopoietic stem cell transplantation in adult with acute leukemia. Leukemia. 2015;29:1069-75.

24. Piemontese S, Ciceri F, Labopin M, Arcese W, Kyrcz-Krzemien S, Santarone S, Huang H, Beelen D, Gorin NC, Craddock C, et al. A comparison between 
allogeneic stem cell transplantation from unmanipulated haploidentical and unrelated donors in acute leukemia. J Hematol Oncol. 2017;10:24.

25. Ruggeri A, Labopin M, Sanz G, Piemontese S, Arcese W, Bacigalupo A, Blaise D, Bosi A, Huang $H$, Karakasis D, et al. Comparison of outcomes after unrelated cord blood and unmanipulated haploidentical stem cell transplantation in adults with acute leukemia. Leukemia. 2015;29:1891-900.

26. Srour SA, Milton DR, Bashey A, Karduss-Urueta A, Al Malki MM, Romee R, Solomon S, Nademanee A, Brown S, Slade M, et al. Haploidentical transplantation with post-transplantation cyclophosphamide for high-risk acute lymphoblastic leukemia. Biol Blood Marrow Transplant. 2017;23:318-24.

27. Bacigalupo A, Ballen K, Rizzo D, Giralt S, Lazarus H, Ho V, Apperley J, Slavin S, Pasquini M, Sandmaier BM, et al. Defining the intensity of conditioning regimens: working definitions. Biol Blood Marrow Transplant. 2009;15:1628-33.

28. Ruggeri A, Labopin M, Ciceri F, Mohty M, Nagler A. Definition of GVHD-free, relapse-free survival for registry-based studies: an ALWP-EBMT analysis on patients with AML in remission. Bone Marrow Transplant. 2016;51:610-1.

29. Przepiorka D, Weisdorf $D$, Martin P, Klingemann HG, Beatty P, Hows J, Thomas ED. 1994 Consensus conference on aGvHD grading. Bone Marrow Transplant. 1995;15:825-8.

30. Lee SJ, Vogelsang G, Flowers ME. Chronic graft versus host disease. Biol Blood Marrow Transplant. 2003;9:215-33.

31. Hoogard P. Frailty model for survival data. Lifetime Data Anal. 1995;1:255-73.

32. Andersen PK, Klein JP, Zhang MJ. Testing for center effects in multi-center survival studies: a Monte Carlo comparison of fixed and random effects tests. Stat Med. 1999:18:1489-500.

33. Giebel S, Labopin M, Socié G, Beelen D, Beelen D, Browne P, Volin L, KyrczKrzemien S, Yakoub-Agha I, Aljurf M, Wu D, et al. Improving results of allogeneic hematopoietic cell transplantation for adults with acute lymphoblastic leukemia in first complete remission: an analysis from the Acute Leukemia Working Party of the European Society for Blood and Marrow Transplantation. Haematologica. 2017;102:139-49.

34. Pavlů J, Labopin M, Zoellner AK, Sakellari I, Stelljes M, Finke J, Fanin R, Stuhler G, Afanasyev BV, Bloor AJ, et al. Allogeneic hematopoietic cell transplantation for primary refractory acute lymphoblastic leukemia: a report from the acute leukemia working party of the EBMT. Cancer. 2017. doi:10.1002/cncr.30604. [Epub ahead of print].

35. Topp MS, Gökbuget N, Stein AS, Zugmaier G, O'Brien S, Bargou RC, Dombret H, Fielding AK, Heffner L, Larson RA, et al. Safety and activity of blinatumomab for adult patients with relapsed or refractory B-precursor acute lymphoblastic leukaemia: a multicentre, single-arm, phase 2 study. Lancet Oncol. 2015;16:57-66.

36. Kantarjian HM, DeAngelo DJ, Stelljes M, Martinelli G, Liedtke M, Stock W, Gökbuget N, O'Brien S, Wang K, Wang T, et al. Inotuzumab ozogamicin versus standard therapy for acute lymphoblastic leukemia. N Engl J Med. 2016;25(375):740-53.

37. Maude SL, Frey N, Shaw PA, Aplenc R, Barrett DM, Bunin NJ, Chew A, Gonzalez VE, Zheng Z, Lacey SF, et al. Chimeric antigen receptor T cells for sustained remissions in leukemia. N Engl J Med. 2014;371:1507-17.

38. Lee DW, Kochenderfer JN, Stetler-Stevenson M, Cui YK, Delbrook C, Feldman SA, Fry TJ, Orentas R, Sabatino M, Shah NN, et al. T cells expressing CD19 chimeric antigen receptors for acute lymphoblastic leukaemia in children and young adults: a phase 1 dose-escalation trial. Lancet. 2015;385:517-28.

39. Rubio MT, Savani BN, Labopin M, Piemontese S, Polge E, Ciceri F, Bacigalupo A, Arcese W, Koc Y, Beelen D, et al. Impact of conditioning intensity in T-replete haplo-identical stem cell transplantation for acute leukemia: a report from the acute leukemia working party of the EBMT. J Hematol Oncol. 2016;9:25.

40. O'Donnell PV, Eapen M, Horowitz MM, Logan BR, DiGilio A, Brunstein C, Fuchs EJ, Flowers ME, Salit R, Raj K, et al. Comparable outcomes with marrow or peripheral blood as stem cell sources for hematopoietic cell transplantation from haploidentical donors after non-ablative conditioning: a matched-pair analysis. Bone Marrow Transplant. 2016;51:1599-601.

41. Castagna L, Crocchiolo R, Furst S, Bramanti S, El Cheikh J, Sarina B, Granata A, Mauro E, Faucher C, Mohty B, et al. Bone marrow compared with peripheral blood stem cells for haploidentical transplantation with a nonmyeloablative conditioning regimen and post-transplantation cyclophosphamide. Biol Blood Marrow Transplant. 2014;20:724-9.

42. Giebel S, Czyz A, Ottmann O, Baron F, Brissot E, Ciceri F, Cornelissen JJ, Esteve J, Gorin NC, Savani B, et al. Use of tyrosine kinase inhibitors to prevent relapse after allogeneic hematopoietic stem cell transplantation for patients with
Philadelphia chromosome-positive acute lymphoblastic leukemia: a position statement of the Acute Leukemia Working Party of the European Society for Blood and Marrow Transplantation. Cancer. 2016;122:2941-51.

43. Dhédin N, Huynh A, Maury S, Tabrizi R, Beldjord K, Asnafi V, Thomas X, Chevallier P, Nguyen S, Coiteux V, et al. Role of allogeneic stem cell transplantation in adult patients with Ph-negative acute lymphoblastic leukemia. Blood. 2015;125:2486-96.

\section{Submit your next manuscript to BioMed Central and we will help you at every step:}

- We accept pre-submission inquiries

- Our selector tool helps you to find the most relevant journal

- We provide round the clock customer support

- Convenient online submission

- Thorough peer review

- Inclusion in PubMed and all major indexing services

- Maximum visibility for your research

Submit your manuscript at www.biomedcentral.com/submit
(O) BioMed Central 